\title{
Relationship between clinical outcomes and nerve conduction studies before and after surgery in patients with carpal tunnel syndrome
}

\author{
Masato Ise ${ }^{1,2}$, Taichi Saito ${ }^{1 *}$, Yoshimi Katayama ${ }^{2}$, Ryuichi Nakahara' ${ }^{1}$, Yasunori Shimamura ${ }^{3}$, Masanori Hamada ${ }^{2}$,
} Masuo Senda ${ }^{2}$ and Toshifumi Ozaki ${ }^{1}$

\begin{abstract}
Background: Nerve conduction study (NCS) is the only useful test for objective assessment of carpal tunnel syndrome (CTS). However, the relationship between pre- and postoperative NCS and clinical outcomes was unclear. This study aimed to determine whether pre- and postoperative ( 6 months) NCS could predict patient-oriented and motor outcomes (6 and 12 months postoperatively) in patients with CTS.
\end{abstract}

Method: Of the 85 patients with CTS, 107 hands were analyzed from March 2011 to March 2020. All patients underwent open carpal tunnel release and were examined using the disabilities of the arm, shoulder and hand (DASH) questionnaire and grip strength (GS) preoperatively and 6 and 12 months postoperatively. Moreover, NCS was examined preoperatively and 6 months postoperatively. Distal motor latency (DML) and sensory conduction velocity (SCV) were the parameters used for NCS. The correlation coefficient between NCS and DASH or GS was calculated. A receiver operating characteristic curve was utilized to determine the NCS threshold value to predict DASH and GS improvement.

Results: The average scores of GS preoperatively and 6 and 12 months postoperatively were 21.3, 22.3, and 22.8, respectively. On the other hand, the average scores of DASH preoperatively and 6 and 12 months postoperatively were 28.8, 18.3, and 12.2, respectively. The average NCS scores (DML and SCV) preoperatively/6 months postoperatively were 7.3/5.4 and 27.8/36.7, respectively. Preoperative NCS did not correlate with DASH and GS. Postoperative SCV correlated with the change in grip strength (6-12 months, $r=0.67 ; 0-12$ months, $r=0.60)$ and DASH $(0-12$ months, $r=0.77)$. Moreover, postoperative DML correlated with the change in DASH (6-12 months, $r=-0.33$; $0-12$ months, $r=-0.59$ ). The prediction for the improvement of GS/DASH achieved a sensitivity of $50.0 \% / 66.7 \%$ and a specificity of $100 \% / 100 \%$, at an SCV cutoff score of 38.5/45.0 or above. The prediction for improvement of GS/DASH achieved a sensitivity of $83.3 \% / 66.7 \%$ and a specificity of $100 \% / 66.7 \%$ at a DML cutoff score of $4.4 / 4.4$ or below.

Conclusion: NCS at 6 months postoperatively can be used to predict the improvement of clinical outcome after 6 months postoperatively in patients with CTS.

Keywords: Carpal tunnel syndrome, Nerve conduction study, The disability of the arm, shoulder and hand questionnaire, Clinical outcomes

\footnotetext{
*Correspondence: umehachi55@gmail.com

1 Department of Orthopaedic Surgery, Okayama University Graduate

School of Medicine, Dentistry and Pharmaceutical Sciences, 2-5-1,

Shikata-cho, Kitaku, Okayama 700-8558, Japan

Full list of author information is available at the end of the article
}

\section{Background}

Carpal tunnel syndrome (CTS) is the most frequent entrapment neuropathy. In the general population, the prevalence of CTS is reported to be $3.8-10 \%[1,2]$, and original author(s) and the source, provide a link to the Creative Commons licence, and indicate if changes were made. The images or other third party material in this article are included in the article's Creative Commons licence, unless indicated otherwise in a credit line to the material. If material is not included in the article's Creative Commons licence and your intended use is not permitted by statutory regulation or exceeds the permitted use, you will need to obtain permission directly from the copyright holder. To view a copy of this licence, visit http://creativecommons.org/licenses/by/4.0/. The Creative Commons Public Domain Dedication waiver (http://creativeco mmons.org/publicdomain/zero/1.0/) applies to the data made available in this article, unless otherwise stated in a credit line to the data. 
among people $>50$ years old in Japan, it is reported to be $5.1 \%[3]$.

Clinical manifestation and physical findings are used to diagnose CTS. Nerve conduction study (NCS) help to diagnose and decide on the treatment plan (conservative treatment or surgery) as well as predict the surgery prognosis for patients with CTS [4]. Furthermore, NCS is the only useful test for objective CTS assessment. NCS and the clinical symptom severity scale were found to be correlated [5]. Moreover, NCS was reported as a predictor of poor outcomes for surgical release [6]. The clinical success of surgical release for CTS occurs at a rate of $75-90 \%$, whereas the recurrence is reported in $4-57 \%$ of cases [7]. Thus, predicting clinical outcomes following surgical release is very useful for patients and surgeons.

However, the relationship between clinical outcomes following surgical release and pre-/postoperative NCS is unclear. In addition, few studies have reported a correlation between NCS and motor outcome (e.g., power or pinch grip). This study aimed to examine the prediction improvement in patient-oriented and motor outcomes after operation using preoperative NCS. Furthermore, whether NCS at 6 months postoperatively can predict clinical outcomes at 12 months postoperatively was investigated.

\section{Methods}

This study analyzed 107 hands of 85 patients with CTS from March 2011 to March 2020. All patients underwent open carpal tunnel release (OCTR), which was performed by two orthopedic hand surgeons. CTS was diagnosed based on the patient's medical history, thenar muscle atrophy, NCS, and physical examination (e.g., ring-finger splitting, Tinel-like sign, and Phalen's test). Electrodiagnostic criteria used to diagnose CTS in this study was median distal motor latency from the wrist to abductor pollicis brevis $<4.0 \mathrm{~ms}$ [8] and median motor nerve conduction velocity $<45 \mathrm{~m} / \mathrm{s}$ from the wrist to abductor pollicis brevis and median sensory nerve conduction velocity $<45 \mathrm{~m} / \mathrm{s}$ in the third digit to wrist [9]. We set the lower limit value of amplitude of compound muscle action potential (CMAP) and sensory nerve action potential (SNAP) of median nerve at wrist stimulation was $3.5 \mathrm{mV}$ and $10 \mu \mathrm{V}$ respectively $[9,10]$.

The patients underwent NCS preoperatively and 6 months postoperatively. Grip strength was also measured, and disabilities of the arm, shoulder and hand (DASH) questionnaire was administered before surgery and at the time of outpatient visits at 6 and 12 months postoperatively. Patients with rheumatoid arthritis, artificial dialysis, polyneuropathy, and unavailable NCS waveform at the median nerve were excluded. Finally, 85 hands of 67 patients were included in this study.
This study was approved by the institutional ethics committee at Okayama University Hospital, and informed consent was obtained in the opt-out form on the website.

NCS was conducted using a Neuropack MEB-2300 (Nihon Kohden, Tokyo, Japan). The filter settings were between 20 and $2000 \mathrm{~Hz}$. Stimulation was performed with a square wave pulse of 0.2 -ms duration. The compound muscle action potential, distal motor latency, and motor nerve velocity of the median nerve were recorded via orthodromic stimulation at the wrist, $70-\mathrm{mm}$ proximal to recording electrodes placed over the abductor pollicis brevis muscle. Sensory nerve conduction velocity $(\mathrm{SCV})$ was recorded via antidromic stimulation at the wrist, $140-\mathrm{mm}$ proximal to recording electrodes placed over the proximal phalanx of the middle finger using ring electrodes around the proximal and middle phalanxes of the middle finger. The skin temperature of the hand was maintained between $32^{\circ} \mathrm{C}$ and $34^{\circ} \mathrm{C}$. Grip strength was measured using Smedley hand dynamometer (Igarashi Ikakougyou, Tokyo, Japan).

Grip strength and DASH were used as parameters for objective and patient-oriented assessments, respectively. DASH is a self-administered questionnaire consisting of a disability/symptom (DASH-DS) scale and two optional modules, namely, work and sport/music modules. Moreover, it was widely used for shoulder, hand, elbow, and wrist problem evaluations. The patients were asked to achieve a score of $1-5$ on all 30 items, and the scores increased with the increase in disability. The obtained raw score was then converted to a $0-100$ scale. The reliability, validity, and responsiveness of the Japanese version of DASH had equivalent evaluation capacity to those of the DASH original versions [11]. Moreover, this study focused on the score of the DASH-DS scale.

The prediction of functional prognosis following surgical release using NCS was explored using the receiver operating characteristic (ROC) curve. A previous study reported the minimal clinically important differences (MCID) for DASH in patients with isolated tendinitis, arthritis, or nerve compression syndromes [12-14]. Therefore, a cutoff score of $>10$ for postoperative clinical improvement in DASH was set. Although no study on the MCID of grip strength in patients with CTS was conducted, the MCID of grip strength was estimated to be $2.69-2.44 \mathrm{~kg}$ in the healthy group without conditions [15]. Thus, we set a cutoff value of $>2 \mathrm{~kg}$ for postoperative clinical grip strength improvement. Moreover, the ROC curve is a commonly used statistical graphical plot to help evaluate the performance of a diagnostic test by plotting the true-positive (sensitivity) rate against the false-positive (1-specificity) rate at various threshold settings. Youden's criterion was used to select the ideal 
cutoff point in order to determine the result of the NCS on the ROC curve. The efficacy of the NCS to predict functional prognosis was described using an area under the curve (AUC), sensitivity, specificity, and positive and negative likelihood ratios.

Statistical analyses were conducted using the Bell Curve (Social Survey Research Information Co., Ltd., Shinjuku-ku, Japan) with the significance level set at $<0.05$ for all statistical tests. The correlations between the results of preoperative NCS and clinical outcomes that include grip strength and DASH score were assessed via a nonparametric test (Spearman's correlation).

\section{Results}

\section{Participant characteristics}

Table 1 presents the patients' characteristics. This study included 67 (18 men and 49 women) patients, and 85 hands with CTS were analyzed. The average age was 64.5 years $([\mathrm{SD}]=13.3$; range $=34-87)$, and the average symptom duration was 19.5 months (range $=2-72$ ). No reoperation cases were included in this study.

NCS and clinical outcomes (grip strength and DASH score) The mean pre-/postoperative values at 6 and 12 months for grip strength, DASH, and NCS results are presented in Table 2. Grip strength at 6 and 12 months postoperatively improved by an average of $1.9 \mathrm{~kg}$ (0-6 months, $95 \%$ confidence interval $[\mathrm{CI}]=0.5-3.4)$ and $3.7 \mathrm{~kg}$ (6-12 months, $95 \% \mathrm{CI}=2.6-4.9)$, respectively, compared

Table 1 Clinical characteristics of patients

\begin{tabular}{ll}
\hline Characteristics & Values \\
\hline Age (years \pm SD) & $64.5 \pm 13.3$ \\
Female ( $/ \%)$ & $49 / 73$ \\
Rt operated hand ( $n$ ) & 49 \\
Duration of symptoms (mo, range) & $19.5(2-72)$ \\
\hline
\end{tabular}

mo months with preoperative measurements. Improvement in grip strength between 6 and 12 months postoperatively was higher compared with that between preoperative and 6 months postoperatively. Grip strength in all patients at 12 months postoperatively improved compared with preoperative measurements. The average DASH scores increased to 11.9 (0-6 months, 95\% CI $=3.2-20.6)$ and 14.1 (6-12 months, 95\% CI $=2.1-26.1)$, respectively. The improvement in DASH score between 6 and 12 months postoperatively was also higher compared with that between preoperatively and 6 months postoperatively. The results of NCS were improved between preoperative and 6 months postoperatively.

\section{Relationships between nerve conduction measures and clinical outcome}

Tables 3 and 4 present the correlation coefficients between pre-/postoperative NCS and change in the grip strength and DASH scores at 6 and 12 months postoperatively. A no significant correlation was observed between preoperative $\mathrm{NCS}(\mathrm{SCV})$ and change in the grip strength scores (0-6 months, $r=0.23$; 6-12 months, $r=0.21 ; 0-12$ months, $r=0.27)$. Moreover, a significant correlation was not observed between preoperative NCS (SCV) and change in DASH scores (0-6 months, $r=0.16$; 6-12 months, $r=-0.03$; $0-12$ months, $r=0.26$ ). $\mathrm{SCV}$ at 6 months postoperatively had modest and significant correlation with the change in grip strength scores (6-12 months, $r=0.67 ; 0-12$ months, $r=0.60)$ and DASH score (0-12 months, $r=-0.59)$. NCS (DML) at 6 months postoperatively had no correlation with the change in grip strength scores but modest and significant correlation with the change in DASH scores (6-12 months, $r=0.12$; 0-12 months, $r=0.77)$.

Similarly, no significant correlation was observed between amplitudes of preoperative CMAP and SNAP and change in the grip strength and DASH scores at 6 and 12 months postoperatively. The amplitude of CMAP at 6 months postoperatively had modest and

Table 2 Average preoperative and postoperative values

\begin{tabular}{|c|c|c|c|c|c|c|}
\hline & \multicolumn{2}{|l|}{ Preoperative } & \multicolumn{2}{|l|}{6 months } & \multicolumn{2}{|l|}{12 months } \\
\hline & Average (SD) & Range & Average (SD) & Range & Average (SD) & Range \\
\hline Grip & $21.3(10.3)$ & $5-61.8$ & $22.3(10.5)$ & $8-69.9$ & $22.8(5.6)$ & $10-35.9$ \\
\hline DASH & $28.8(19.5)$ & $0-94.4$ & $18.3(13.5)$ & $0-49.1$ & $12.2(8.5)$ & $1-28$ \\
\hline \multicolumn{7}{|l|}{ Median } \\
\hline DML & $7.3(6.6)$ & $4-18.2$ & $5.4(5.9)$ & $0-8.0$ & & \\
\hline SCV & $27.8(7.3)$ & $9.4-46.8$ & $36.7(10.7)$ & $0-54.9$ & & \\
\hline CMAP amplitude & $3.8(3.0)$ & $0.1-12.7$ & $4.2(3.0)$ & $0-12.0$ & & \\
\hline
\end{tabular}

DASH Disabilities of Arm, Shoulder and Hand, DML Distal motor latency (ms), SCV Sensory conduction velocity (m/s), CMAP Compound muscle action potential (mV), SNAP Sensory nerve action potential $(\mu \mathrm{V})$, SD Standard deviation 
Table 3 Spearman's correlation coefficients between preoperative nerve conduction measures and difference in grip strength and DASH

\begin{tabular}{|c|c|c|c|}
\hline Instrument scale & 0-6 Difference of GP & 6-12 Difference of GP & $\begin{array}{l}0-12 \text { Dif- } \\
\text { ference of } \\
\text { GP }\end{array}$ \\
\hline DML (ms) & -0.26 & 0.07 & -0.15 \\
\hline $\mathrm{SCV}(\mathrm{m} / \mathrm{s})$ & 0.23 & 0.21 & 0.27 \\
\hline CMAP amplitude (mV) & 0.04 & -0.07 & -0.36 \\
\hline SNAP amplitude $(\mu \mathrm{V})$ & 0.04 & 0.14 & 0.13 \\
\hline Instrument scale & 0-6 Difference of DASH score & 6-12 Difference of DASH score & $\begin{array}{l}\text { 0-12 Dif- } \\
\text { ference } \\
\text { of DASH } \\
\text { score }\end{array}$ \\
\hline DML (ms) & -0.01 & -0.1 & -0.03 \\
\hline $\mathrm{SCV}(\mathrm{m} / \mathrm{s})$ & 0.16 & -0.03 & 0.26 \\
\hline CMAP amplitude (mV) & -0.16 & -0.28 & -0.49 \\
\hline SNAP amplitude $(\mu \mathrm{V})$ & -0.20 & 0.28 & 0.11 \\
\hline
\end{tabular}

Table 4 Spearman's correlation coefficients between 6 months postoperative nerve conduction measures and difference in grip strength and DASH

\begin{tabular}{|c|c|c|c|}
\hline Instrument scale & 0-6 Difference of GP & 6-12 Difference of GP & $\begin{array}{l}0-12 \text { Dif- } \\
\text { ference of } \\
\text { GP }\end{array}$ \\
\hline Post 6 month DML & -0.24 & -0.002 & -0.13 \\
\hline Post 6 month SCV & 0.31 & $0.67^{*}$ & 0.60 \\
\hline Post 6 month CMAP & $0.41^{*}$ & 0.43 & -0.04 \\
\hline Post 6 month SNAP & 0.12 & 0.08 & -0.19 \\
\hline Instrument scale & 0-6 Difference of DASH score & 6-12 Difference of DASH score & $\begin{array}{l}\text { 0-12 Dif- } \\
\text { ference } \\
\text { of DASH } \\
\text { score }\end{array}$ \\
\hline Post 6 month DML & $0.60^{*}$ & 0.12 & $0.77^{*}$ \\
\hline Post 6 month SCV & -0.23 & -0.33 & -0.59 \\
\hline Post 6 month CMAP amplitude & 0.26 & -0.23 & -0.45 \\
\hline Post 6 month SNAP amplitude & -0.07 & 0.09 & -0.38 \\
\hline
\end{tabular}

${ }^{*} P<0.05$

significant correlation with the change in grip strength scores $(0-6$ months, $r=0.41 ; 6-12$ months, $r=0.43$; $0-12$ months, $r=-0.04)$.

We also compared the postoperative clinical outcomes between two groups divided by the lower limit of the CMAP amplitude $(3.5 \mathrm{mV})$ at pre- and 6 months post-surgery to investigate the effect of the electrophysiologic pathology on clinical outcomes. There was no significant difference between the two groups (Supplementary Tables 1 and 2).
Area under the curve in the receiver operating characteristic curve analysis

An NCS ROC analysis at 6 months postoperatively (SCV, DML) was conducted to set a cutoff point for predicting grip strength and DASH improvements at 12 months. The SCV results on grip strength demonstrated that the AUC was 0.67 (Fig. 1; 95\% CI for AUC, 0.20-1,13). A cutoff value of $38.5 \mathrm{~m} / \mathrm{s}$ higher for SCV predicts improvement with sensitivity and specificity of 50.0 and 100\%, respectively. The DML results indicated that the AUC 


\section{ROC curve}

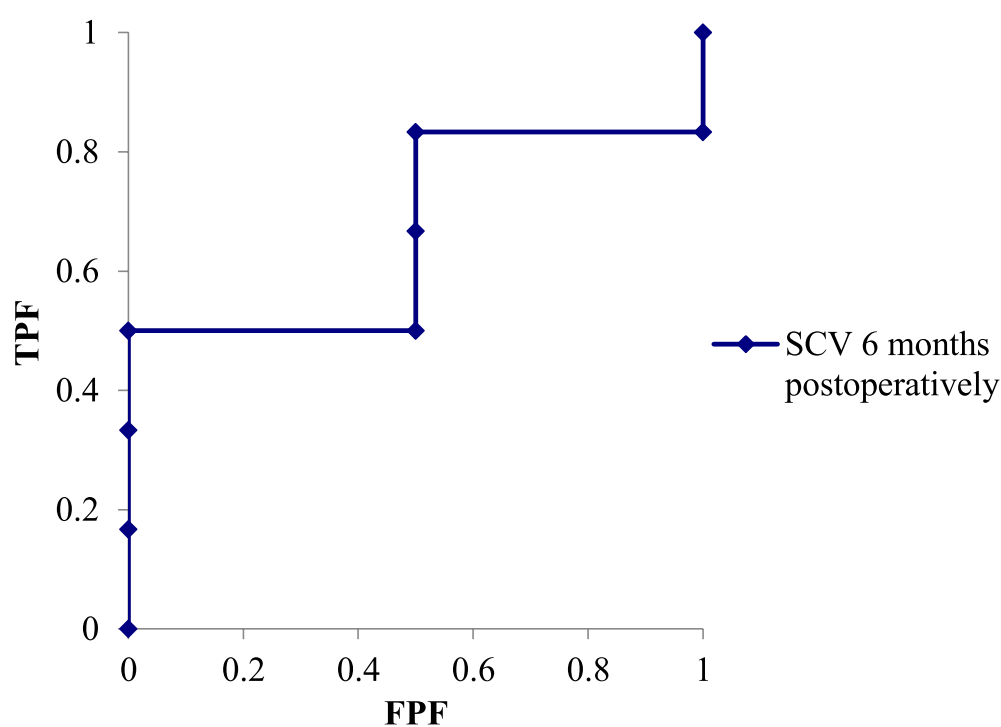

Fig. 1 A graph showing the ROC curve for predicting improvement of $>2 \mathrm{~kg}$ in grip strength based on SCV at 6 months postoperatively. The actual area under the curve (AUC,0.67 [95\% Cl, 0.20 to 1.13]). The best cutoff point of SCV for balancing sensitivity and specificity was 38.5

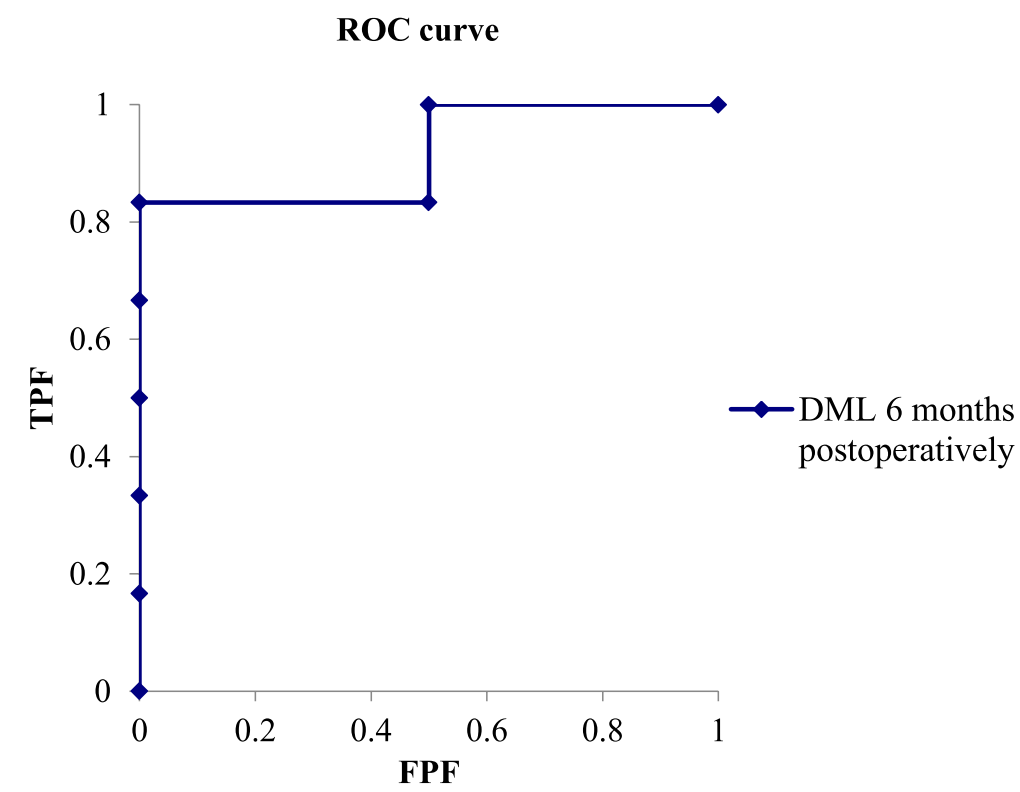

Fig. 2 A graph showing the ROC curve for predicting improvement of $>2 \mathrm{~kg}$ in grip strength based on DML at 6 months postoperatively. The actual area under the curve (AUC,0.91 [95\% Cl, 0.69 to 1.15]). The best cutoff point of DML for balancing sensitivity and specificity was 4.4

was 0.91 (Fig. 2; 95\% CI for AUC, 0.69-1.15). A cutoff value of $4.4 \mathrm{~ms}$ lower for DML predicts improvement with sensitivity and specificity of 83.3 and $100 \%$, respectively. The SCV results on DASH improvement indicated that the AUC was 0.83 (Fig. 3; 95\% CI for AUC, 0.481,19). A cutoff value of $45.0 \mathrm{~m} / \mathrm{s}$ lower for SCV predicts improvement with sensitivity and specificity of 66.7 and $100 \%$, respectively. The DML results demonstrated that the AUC was 0.72 (Fig. 4; 95\% CI for AUC, 0.33-1,11). A cutoff value of $4.4 \mathrm{~ms}$ higher for DML predicts improvement with sensitivity and positive predictive value of 66.7 and $66.7 \%$, respectively. 


\section{ROC curve}

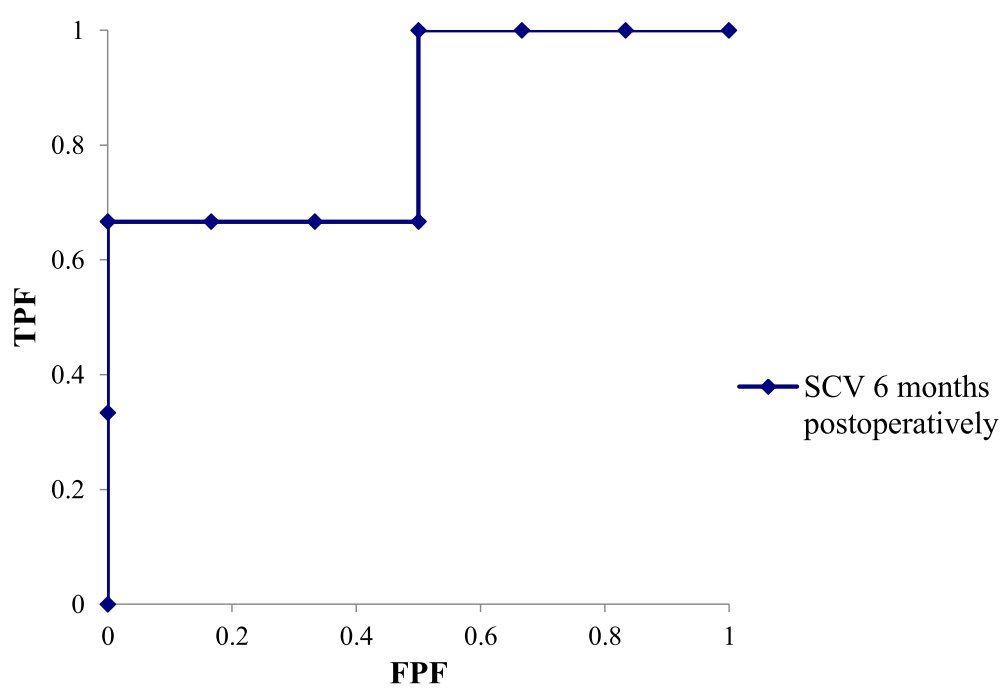

Fig. 3 A graph showing the ROC curve for predicting improvement of $>10$ in the DASH score based on SCV at 6 months postoperatively. The actual area under the curve (AUC,0.83 [95\% Cl, 0.48 to 1.19]). The best cutoff point of SCV for balancing sensitivity and specificity was 45.0

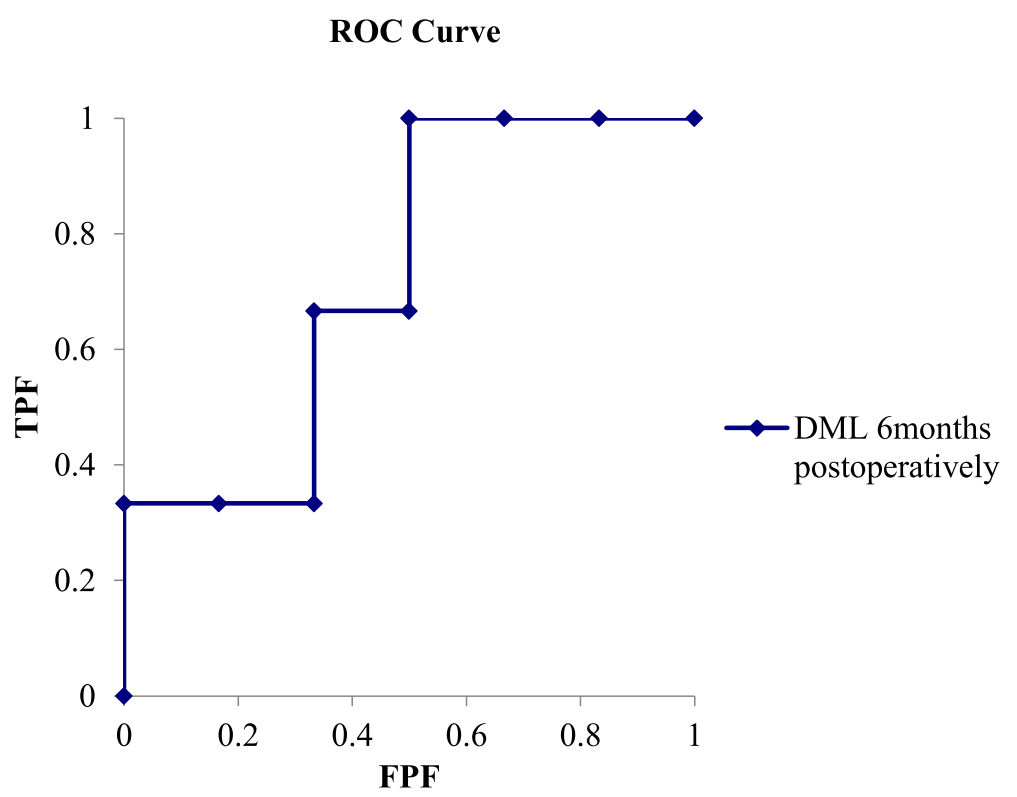

Fig. 4 A graph showing the ROC curve for predicting improvement of $>10$ in the DASH score based on DML at 6 months postoperatively. The actual area under the curve (AUC, $0.72[95 \% \mathrm{Cl}, 0.33$ to 1.11$]$ ). The best cutoff point of DML for balancing sensitivity and specificity was 4.4

\section{Discussion}

This retrospective study found a moderate and significant correlation between NCS (SCV) and the change in the grip strength and DASH scores at 6 and 12 months postoperatively. However, a no significant correlation exists between preoperative NCS and clinical outcomes (DASH and grip strength).
The clinical success rate of OCTR was reported to be about $75-90 \%$ [16]. Thus, the prediction of postoperative clinical outcomes for patients and surgeon is beneficial. For surgeons, the prediction of the postoperative clinical course is helpful for the selection of patients with poor prognoses as well as explanations for patients and considerations for operation. Several studies were conducted 
using NCS and patient-reported outcomes (PRO) to predict prognosis following operation $[6,17,18]$. However, there are conflicting reports on the severity of conduction disturbances and surgery outcomes. Heybeli et al. reported that NCS improvements did not correlate with improvement in the self-administered Boston Questionnaire preoperatively and 6 months preoperatively [19]. Itubo et al. also reported that no significant correlation was observed between the preoperative and 3 months postoperative patient-oriented questionnaires and preoperative and 3 months postoperative NCS [18]. On the other hand, Bland et al. reported that preoperative NCS correlated with postoperative clinical outcomes and that patients with middle-grade abnormalities achieved better results compared with those with severe abnormalities [6]. This study demonstrated a no significant correlation between preoperative NCS and improvement in clinical outcomes (grip strength and DASH). In addition, the follow-up period was short (within 6 months) in most studies that investigated the correlation between postoperative clinical outcomes and NCS [13, 18, 20]. Furthermore, this study revealed that a significant and modest correlation was observed between NCS (SCV) at 6 months postoperatively and the change in grip strength and DASH at 12 months postoperatively.

Setting a threshold value is useful for determining CTS severity and predicting clinical outcome prognosis following operation. Concerning the threshold value of NCS, Bland et al. reported that distal motor latency to abductor pollicis brevis $<6.5 \mathrm{~ms}$ was utilized to evaluate the severity of CTS [21]. In addition, Lo et al. reported that a cutoff value of $6.0 \mathrm{~ms}$ or lower for preoperative sensory latency predicts a good outcome (in terms of paresthesia score) with sensitivity/certainty and positive predictive values of 84.6 and $86.8 \%$, respectively, in patients with CTS following endoscopic carpal tunnel syndrome surgery [13]. This study revealed the improvement in grip strength/DASH at 12 months postoperatively in patients with $>38.5 \mathrm{~m} / \mathrm{s}(\mathrm{SCV})$ and $<4.4 \mathrm{~ms}$ $(\mathrm{DML}) />45.0 \mathrm{~m} / \mathrm{s}(\mathrm{SCV})$ and $<4.4 \mathrm{~ms}$ (DML) at 6 months postoperatively, respectively. To the best of our knowledge, this study is the first to reveal the NCS threshold value to predict $\mathrm{PRO}$ and grip strength improvement following surgery. Nolan et al. reported that even at 66 months postoperatively, only $50 \%$ of hands demonstrated normal DML [22]. This study demonstrated that $2.4 \% / 1.2 \%$ of hands exhibited normal DML/SCV preoperatively, and $23 \% / 44 \%$ of hands exhibited normal DML/ $\mathrm{SCV}$ at 6 months postoperatively. Even if the results of NCS at 6 months postoperatively are not normal, the results of this study can help predict improvements in grip strength and DASH. Thus, these results suggested that NCS at 6 months postoperatively can be used not only to evaluate the degree of postoperative NCS improvement but also to predict the improvement in grip strength/DASH at 12 months postoperatively.

This study used grip strength for postoperative clinical motor evaluation. However, there is no consensus as to what method for motor function assessment of patients with CTS following surgical treatment is the most useful [23]. However, grip strength was one of the major objective motor outcomes. Yoshida et al. reported the grip strength-related disability of the upper extremity in patients with CTS [24]. Some other studies also used grip strength as motor outcomes in patients with CTS following surgery [25-29].

Grip strength at 6 months postoperatively decreased in $40 \%$ of the patients compared with the preoperative measurement. However, grip strength improved from preoperative levels in all patients who were followed up at 12 months postoperatively. Scar pain or tenderness may influence grip strength weakness at 6 months postoperatively.

The follow-up period in this study is limited to 1 year. Thus, whether NCS at 6 months postoperatively will be related to long-term (more than 1 year) follow-up was not determined. According to the preceding study, the clinical outcomes following surgical release improved up to 6 months postoperatively. The same outcome was obtained after 6 years [30]. De Kleermaeker et al. investigated the long-term outcome after operation in patients with CTS at 8 months postoperatively and the median follow-up at 9 years. They reported that the most important factor associated with the long-term outcome is treatment outcome after about 8 months, and its effect persists after 9years [16]. Atroshi et al. also reported the clinical outcome at 1 year postoperatively, which was maintained at the final follow-up (11-16years) [31]. Although the evaluation of outcomes and NCS in this study was conducted within a year, clinical outcome prognosis at 1 year postoperatively may represent a long period of functional prognosis of more than 1 year.

Neurophysiological severity of CTS median nerve may affect postoperative clinical outcomes. The postoperative CMAP amplitude had significant correlation with change in the grip strength at 6 months postoperatively. However, there was no significant difference in postoperative clinical outcomes between the two groups divided by the lower limit of CMAP amplitudes in this study. We evaluated only the amplitude, though the amplitude and duration of CMAP are required to correctly distinguish between axonal loss and demyelinating conduction block. The limitation may have influenced on the outcomes.

Patients with unavailable NCS (MCV and SCV) waveform at the median nerve were excluded. Therefore, the very severe cases with no available waveform were not 
included in this study. Thus, the result of this study may not be applied to patients with very severe CTS.

\section{Conclusions}

This study found that preoperative NCS is not used to predict postoperative clinical outcomes. However, the results of the 6 months postoperative NCS can predict the improvement in the DASH score at 12 months postoperatively.

\section{Supplementary Information}

The online version contains supplementary material available at https://doi. org/10.1186/s12891-021-04771-y.

Additional file 1: Supplementary Table 1. Comparison of average difference of grip strength and DASH between two groups divided by the lower limit of preoperative CMAP amplitudes. Supplementary Table 2. Comparison of average difference of grip strength and DASH between two groups divided by the lower limit of 6 months postoperative CMAP amplitudes.

\section{Acknowledgments}

The authors would like to thank Enago (www.enago.jp) for the English language review.

\section{Authors' contributions}

Conception and research design: TS, RN, MS, and TO. Data acquisition: MI, TS, YK, YS, MH, and MS. Data analysis and interpretation: RN, ST, MI, MH, MS, and TO. Statistical analyses: RN and MI. Drafting of the article: MI and TS. All other authors contributed to writing and revising the manuscript for scientific content and approved the final version before submission.

\section{Funding}

This study was supported by the following grants: the Japan Society for the Promotion of Science (JSPS, grant number 18K16662). This funding sources had no further role in the study design, data collection, analysis and interpretation of data, the writing of the manuscript; the decision to publish.

\section{Availability of data and materials}

The datasets used and analyzed during the current study are available from the corresponding author on reasonable request.

\section{Declarations}

\section{Ethics approval and consent to participate}

This study was designed as a single-center retrospective cohort study and was approved by the Ethic Committee of Okayama University Hospital (approval No. K2009-006). All methods were carried out in accordance with guidelines and regulations of Okayama University Hospital.

We have obtained informed consent in the form of opt-out on the web-site from patients.

\section{Consent for publication}

Not applicable.

\section{Competing interests}

The authors declare no competing interests.

\section{Author details}

'Department of Orthopaedic Surgery, Okayama University Graduate School of Medicine, Dentistry and Pharmaceutical Sciences, 2-5-1, Shikata-cho, Kitaku, Okayama 700-8558, Japan. ${ }^{2}$ Department of Rehabilitation Medicine, Okayama University Hospital, Okayama, Japan. ${ }^{3}$ Department of Sports Medicine,
Okayama University Graduate School of Medicine, Dentistry and Pharmaceutical Sciences, Okayama, Japan.

Received: 21 April 2021 Accepted: 4 October 2021

Published online: 16 October 2021

\section{References}

1. Atroshi I, Gummesson C, Johnsson R, Ornstein E, Ranstam J, Rosen I. Prevalence of carpal tunnel syndrome in a general population. JAMA. 1999;282(2):153-8.

2. de Krom MC, Knipschild PG, Kester AD, Thijs CT, Boekkooi PF, Spaans F. Carpal tunnel syndrome: prevalence in the general population. J Clin Epidemiol. 1992;45(4):373-6.

3. Hashimoto S, Ikegami S, Nishimura H, Uchiyama S, Takahashi J, Kato H. Prevalence and risk factors of carpal tunnel syndrome in Japanese aged 50 to 89 years. J Hand Surg Asian Pac Vol. 2020;25(3):320-7.

4. Jordan R, Carter T, Cummins C. A systematic review of the utility of electrodiagnostic testing in carpal tunnel syndrome. Br J Gen Pract. 2002;52(481):670-3.

5. You H, Simmons Z, Freivalds A, Kothari MJ, Naidu SH. Relationships between clinical symptom severity scales and nerve conduction measures in carpal tunnel syndrome. Muscle Nerve. 1999;22(4):497-501.

6. Bland JD. Do nerve conduction studies predict the outcome of carpal tunnel decompression? Muscle Nerve. 2001;24(7):935-40.

7. Louie D, Earp B, Blazar P. Long-term outcomes of carpal tunnel release: a critical review of the literature. Hand (NY). 2012;7(3):242-6.

8. Goldfarb CA. The clinical practice guideline on carpal tunnel syndrome and workers' compensation. J Hand Surg Am. 2016;41(6):723-5.

9. Kimura J. Electrodiagnosis in diseases of nerve and muscle: principles and practice. Muscle Nerve. 1983;7(6):500-1.

10. Buchthal F, Rosenfalck A. Sensory conduction from digit to palm and from palm to wrist in the carpal tunnel syndrome. J Neurol Neurosurg Psychiatry. 1971;34(3):243-52.

11. Imaeda T, Toh S, Nakao Y, Nishida J, Hirata H, ljichi M, et al. Validation of the Japanese Society for Surgery of the Hand version of the Disability of the Arm, Shoulder, and Hand questionnaire. J Orthop Sci. 2005;10(4):353-9.

12. Franchignoni F, Vercelli S, Giordano A, Sartorio F, Bravini E, Ferriero G. Minimal clinically important difference of the disabilities of the arm, shoulder and hand outcome measure (DASH) and its shortened version (QuickDASH). J Orthop Sports Phys Ther. 2014;44(1):30-9.

13. Lo YL, Lim SH, Fook-Chong S, Lum SY, Teoh LC, Yong FC. Outcome prediction value of nerve conduction studies for endoscopic carpal tunnel surgery. J Clin Neuromuscul Dis. 2012;13(3):153-8.

14. Roy JS, MacDermid JC, Woodhouse LJ. Measuring shoulder function: a systematic review of four questionnaires. Arthritis Rheum. 2009;61(5):623-32.

15. Villafañe $J H$, Valdes K, Bertozzi L, Negrini S. Minimal clinically important difference of grip and pinch strength in women with thumb carpometacarpal osteoarthritis when compared to healthy subjects. Rehabil Nurs. 2017:42(3):139-45.

16. De Kleermaeker F, Meulstee J, Bartels R, Verhagen WIM. Long-term outcome after carpal tunnel release and identification of prognostic factors. Acta Neurochir. 2019;161(4):663-71.

17. Giannini F, Cioni R, Mondelli M, Padua R, Gregori B, D'Amico P, et al. A new clinical scale of carpal tunnel syndrome: validation of the measurement and clinical-neurophysiological assessment. Clin Neurophysiol. 2002;113(1):71-7.

18. Itsubo T, Uchiyama S, Momose T, Yasutomi T, Imaeda T, Kato H. Electrophysiological responsiveness and quality of life (QuickDASH, CTSI) evaluation of surgically treated carpal tunnel syndrome. J Orthop Sci. 2009:14(1):17-23.

19. Heybeli N, Kutluhan S, Demirci S, Kerman M, Mumcu EF. Assessment of outcome of carpal tunnel syndrome: a comparison of electrophysiological findings and a self-administered Boston questionnaire. J Hand Surg Br. 2002;27(3):259-64

20. Conzen C, Conzen M, Rübsamen N, Mikolajczyk R. Predictors of the patient-centered outcomes of surgical carpal tunnel release - a prospective cohort study. BMC Musculoskelet Disord. 2016;17:190. 
21. Bland JD. A neurophysiological grading scale for carpal tunnel syndrome. Muscle Nerve. 2000;23(8):1280-3.

22. Nolan WB 3rd, Alkaitis D, Glickel SZ, Snow S. Results of treatment of severe carpal tunnel syndrome. J Hand Surg Am. 1992;17(6):1020-3.

23. Greenslade JR, Mehta RL, Belward P, Warwick DJ. Dash and Boston questionnaire assessment of carpal tunnel syndrome outcome: what is the responsiveness of an outcome questionnaire? J Hand Surg Br. 2004;29(2):159-64.

24. Yoshida A, Kurimoto S, Iwatsuki K, Saeki M, Nishizuka T, Nakano T, et al. Upper extremity disability is associated with pain intensity and grip strength in women with bilateral idiopathic carpal tunnel syndrome. NeuroRehabilitation. 2019;44(2):199-205.

25. Gellman H, Kan D, Gee V, Kuschner SH, Botte MJ. Analysis of pinch and grip strength after carpal tunnel release. J Hand Surg Am. 1989;14(5):863-4.

26. Bednarski M, Zyluk A, Zyluk B. Changes of grip and pinch strength after carpal tunnel release. Chir Narzadow Ruchu Ortop Pol. 2005;70(1):21-6.

27. Young VL, Logan SE, Fernando B, Grasse P, Seaton M, Young AE. Grip strength before and after carpal tunnel decompression. South Med J. 1992:85(9):897-900
28. Sayegh ET, Strauch RJ. Open versus endoscopic carpal tunnel release: a meta-analysis of randomized controlled trials. Clin Orthop Relat Res. 2015;473(3):1120-32.

29. Singh GK, Srivastava S. Grip strength of occupational workers in relation to carpal tunnel syndrome and individual factors. Int J Occup Saf Ergon. 2020;26(2):296-302

30. Pensy RA, Burke FD, Bradley MJ, Dubin NH, Wilgis EF. A 6-year outcome of patients who cancelled carpal tunnel surgery. J Hand Surg Eur Vol. 2011:36(8):642-7.

31. Atroshi I, Gummesson C, Johnsson R, Ornstein E. Diagnostic properties of nerve conduction tests in population-based carpal tunnel syndrome. BMC Musculoskelet Disord. 2003;4:9.

\section{Publisher's Note}

Springer Nature remains neutral with regard to jurisdictional claims in published maps and institutional affiliations.
Ready to submit your research? Choose BMC and benefit from:

- fast, convenient online submission

- thorough peer review by experienced researchers in your field

- rapid publication on acceptance

- support for research data, including large and complex data types

- gold Open Access which fosters wider collaboration and increased citations

- maximum visibility for your research: over $100 \mathrm{M}$ website views per year

At BMC, research is always in progress.

Learn more biomedcentral.com/submissions 